\title{
SCREENING OF ENVIRONMENTAL IMPACT OF POLLUTION WITH THE QGIS PLUGIN ENVIFATE
}

\author{
F. Geri ${ }^{* a}$, O. Cainelli a ${ }^{\text {, G. Salogni }}{ }^{\text {b }}$ P. Zatelli ${ }^{\text {a }}$, M. Ciolli ${ }^{\text {a }}$ \\ a Department of Civil, Environmental and Mechanical Engineering, University of Trento, via Mesiano 77, 38123 Trento, Italy - \\ (francesco.geri, oscar.cainelli, paolo.zatelli, marco.ciolli)@unitn.it \\ b Giunta Regionale del Veneto - Area Tutela e Sviluppo del Territorio - Direzione Commissioni Valutazioni - Unità Organizzativa \\ Commissioni VAS VINCA NUVV - PO Pianificazione ambientale - Gianluca.Salogni@regione.veneto.it
}

Commission IV, WG IV/4

KEY WORDS: GIS, Contamination modelling, python, QGIS, environment

\begin{abstract}
:
Public and academic interest in environmental pollution caused by toxic substances and other sources, like noise, is constantly raising. To protect public health and ecosystems it is necessary to maintain the concentrations of pollutants below a safety threshold. In this context the development of models able to assess environmental pollution impact has been identified as a priority for future research. Scientific community has therefore produced many predictive models in the field. The vast majority of them needs to be run by specialists with a deep technical knowledge of the modeled phenomena in order to process the data and understand the results and it is not feasible to use this models for simple prescreening activities. Planners, evaluators and technical operators need reliable, usable and simple tools in order to carry out screening analysis of impact assessment.

The ENVIFATE software is currently under development by the Department of Civil, environmental and mechanical engineering of the University of Trento, Italy, in the frame of a project funded by the Italian Veneto Region with the aim to make available to nonspecialists screening analysis to assess the risks of a set of possible environmental pollution sources in protected areas.

The development of ENVIFATE follows these basic requirements: i) Open-Source ii) multiplatform iii) user friendly iv) GIS oriented. In order to respect these principles we have chosen to develop a plugin of QGIS, using python as a development language and creating a module for each environmental compartment analyzed: rivers, lakes, atmospheric dispersion, dispersion in groundwater and noise.

The plugin architecture is composed of a series of core functions characterized by command line interfaces that can be called from third-party applications (such as Grass GIS), connectable in custom data flows and with a high level of modularity and scalability. The base of the different models are highly tested and reliable algorithms adopted by the Italian Institute for Protection and Environmental Research (Istituto Superiore per la Protezione e la Ricerca Ambientale - ISPRA). Due to their simplicity, and for safety reasons, the structure of these models is constrained to provide conservative results, so to overestimate actual risk. This approach allows to provide statistically validated instruments to be used in different environmental contexts. All modules of the plugin provide numerical and cartographical results: in particular the command-line interface provides "static" results, or linked to a particular spatial and temporal state, while the Qgis plugins iterate the single analysis along space and time in order to provide georeferenced maps and time distributed results.
\end{abstract}

\section{INTRODUCTION}

No more than 60 years ago, public authorities advised to throw waste into rivers as the best behavior to follow for a right resource management: "By sensible definition any by-product of a chemical operation for which there is no profitable use is a waste. The most convenient, least expensive way of disposing of said waste - up the chimney or down the river - is the best" (Haynes, 1954). Environmental law has become an important and evolving component of international law only starting from the 1980s (Tarlock, 2009). Earlier, for most of the 20th century, many industries were freed of their waste of processing, solids or liquids, simply by throwing them into the environment with the load of pollutants reaching unsustainable environmental peaks with serious consequences for human health (Hemond \& Fechner, 2014). For example, a research of The Global Burden of Disease (GBD) shows that exposure to ambient fine particulate matter (PM2.5) is the seventh most important risk factor contributing to global mortality, responsible for 2.9 million premature deaths in the world in 2013 (Forouzanfar et al. 2015). Furthermore, some model projections based on a business-as-usual emission scenario indicate that the contribution of outdoor air pollution to premature mortality could double by 2050 (Lelieveld et al., 2015). Other examples regards groundwater, one of the main resource as a drinking water, that every year worldwide is polluted from hundreds of millions of tonnes of spilled waste into the environment, many of which contain radioactive materials (Schwarzenbach et al, 2010).

Despite all these adverse impacts of pollution, it is not possible for modern societies to stop all usage or environmental release of chemicals, but it is essential to have tools to assess the fate and the effect of polluting substances introduced into the environment, in order to define planning strategies that are really suitable for human health and environmental protection (Tarlock, 2009).

In this context, the use of geographical information system (GIS) increases the potential for using fate and transport models through the production of scenarios where the estimated

Corresponding author 
concentration is distributed in space in form of thematic maps (Schwarzenbach et al., 2010; Gulliver et al., 2011).

In 2016, the Italian Veneto Region funded a research project at the University of Trento, Italy, in order to develop a set of GIS tools for a preliminary environmental risk assessment. The features that these tools ought to have are: i) GIS oriented, ii) open Source, iii) statistically robust, iv) suitable, v) crossplatform.

The core concept in which the models have to work is the precautionary principle: the plugin should be used to evaluate if the risk to overcoming the legal threshold of substance concentration in the environment exists. If this risk is present, the authorities can carry on the analysis with the aid of more sophisticated models and software tools.

The aim of this paper is to present a QGIS plugin called ENVIFATE that allows the estimation of the concentration of pollutants crossing the following environmental matrices: i) surface water, ii) groundwater, iii) atmosphere, iv) lagoon, v) noise pollution.

The purpose of ENVIFATE is to make available a screening analysis method that would allow the assessment of the existence of potential risk of environmental contamination, due to existing or planned human activities.

The ENVIFATE project is actually in progress and its various components are in development. As for now ground water, surfarce water (river and lake) and atmospheric (smokestack) models have been completed.

\section{METHODS}

\subsection{Development environment}

After a careful bibliographic research of available models and software, it was chosen to implement the ENVIFATE tools as a QGIS plugins. QGIS is a user friendly Open Source Geographic Information System (GIS) licensed under the GNU General Public License. QGIS is an official project of the Open Source Geospatial Foundation (QGIS Development Team, 2017). It runs on Linux, Unix, Mac OSX, Windows and Android and supports numerous vector, raster, and database formats and functionalities. One of the main feature of QGIS is the possibility to extend the basic functionality through a plugins system that allows many new features/functions to be easily added to the application. The plugins are written in the Python language, one of the main scripting language suitable also for object oriented programming and distributed application, completely open source, and they are stored in external repositories and maintained by the individual authors.

These characteristics suggested that QGIS as the best choice for ENVIFATE implementation.

\subsection{Model implentation}

At the base on ENVIFATE there are tested and reliable analytical models in order to obtain reliable and defensible results from statistical point of view. Algorithms used in these models are compatible with guidelines provided by ISPRA, the italian insitute of research and protection of environment, and in particular with the specifications in the official document "Methodological criteria for the application of the absolute risk analysis of contaminated sites" (ISPRA, 2008), containing a series of analytical models for predicting pollution concentration considering different transport factors.

These models follows the Tier 2 site evaluation process (ASTM E-1739, 2015), providing conservative first step results in terms of pollutant transport, leading to overestimation of pollution and risk levels.

Below the analytical models implemented in ENVIFATE are briefly described. For further details, please refer to the documents citated in the text.

2.2.1 Groundwater model: it is based on a twodimensional analytical model that allows to estimate the pollutant concentration within the saturated soil portion. It consists of 2 sub-modules that work in sequence: leaching and Diluction Attenuation Factor (DAF).

Leaching represents the soil infiltration of rainwater that, coming in contact with the contaminants, produces an eluate that crosses the unsaturated layer until reaching the groundwater (saturated layer).

$$
L F=\frac{K_{w s} * S A M}{L D F}
$$

where $\quad \mathrm{K}_{\mathrm{ws}}=$ subdivision coefficient soil-water

SAM = soil coefficient of attenuation

$\mathrm{LDF}=$ dilution factor

The Diluction Attenuation Factor (DAF) expresses the ratio between the concentration of a contaminant at the polluting source and the concentration at the exposure point located at a certain distance from the source in the groundwater flow direction (ISPRA, 2008).

It assumes that the pollutant distributes instantly throughout the vertical section of the mixing zone, eliminating de facto the $\mathrm{z}$ axis. It is based on the Domenico model (Domenico \& Schwartz, 1998).

$$
\begin{gathered}
\frac{C(x, y)}{C_{0}}=\frac{1}{2} \exp \left[\frac{x}{2 \alpha_{x}}\left(1-\sqrt{1+\frac{4 \lambda \alpha_{x} R}{v}}\right)\right] \\
{\left[\operatorname{erf}\left(\frac{y+0.5 S}{2 \sqrt{\left(\alpha_{y} x\right)}}\right)-\operatorname{erf}\left(\frac{y-0.5 S}{2 \sqrt{\left(\alpha_{y} x\right)}}\right)\right]}
\end{gathered}
$$

where $\quad \mathrm{C}(\mathrm{x}, \mathrm{y})=$ concentration at coordinates $\mathrm{x}, \mathrm{y}$ $\mathrm{C}_{0}=$ source pollutant concentration $\mathrm{R}=$ delay factor $\mathrm{S}=$ source extension $\mathrm{v}=$ Darcy velocity $\lambda=$ first order biodegradation coefficient $\alpha_{\mathrm{x}}, \alpha_{\mathrm{y}}=$ dispersion indexes $\mathrm{x}, \mathrm{y}=$ coordinates

2.2.2 River model: it is based on a Fickian model of turbulent dispersion of the pollutant in the direction of river flow. The model use slope and roughness parameters to calculate the instantly velocity of the river, which is the basis of the level of pollutant dispersion. The model is one-dimensional assuming the instantaneous mixing throughout the cross-section of the river (Hemond \& Fechner, 2014).

$$
C(x, t)=\frac{M_{a}}{\sqrt{4 \pi D_{L} t}} \mathrm{e}^{-(x-V t)^{2} /\left(4 D_{L} t\right)} \mathrm{e}^{-k t}
$$

where $\quad \mathrm{M}_{\mathrm{a}}=$ pollutant mass

$\mathrm{D}_{\mathrm{L}}=$ longitudinal Fickian transport coefficient

$\mathrm{t}=$ time from injection

$\mathrm{V}=$ mean river velocity 
$\mathrm{x}=$ distance from source

$\mathrm{k}=$ first order decay index

2.2.3 Lake model: uses the same analytical model of the river module. The difference concerns the lake water velocity and the Fickian dispersion index that is divided into the $\mathrm{x}$ and $\mathrm{y}$ component. The model is applied with a logical raster, producing a concentration result map (Hemond \& Fechner, 2014).

$$
C(x,, y, t)=\frac{M_{a}}{4 \pi t \sqrt{D_{x} D_{y}}} \mathrm{e}^{-\left((x-V t)^{2} /\left(4 D_{x} t\right)+(y-V t)^{2} /\left(4 D_{y} t\right)\right)} \mathrm{e}^{-k t}
$$

2.2.4 Atmosphere model: it is based on the gaussian Pasquill-Gifford stationary model. The Pasquill-Gifford model is a suitable analytical solution in case of constant rate emissions, such as a smokestack, assuming a constant wind direction and intensity. The atmospheric stability classes allow the model to be adapted to different climate conditions. The model estimates the pollutant concentraton that reach the ground level (Pasquill, 1961).

$$
C=\frac{Q}{u} \frac{g_{1} g_{2}}{2 \pi \sigma_{y} \sigma_{z}}
$$

where $\quad \mathrm{Q}=$ pollutant mass

$\mathrm{u}=$ wind main speed

$\mathrm{g}=$ gaussian disturbance factor

$\sigma_{\mathrm{y}}, \sigma_{\mathrm{z}}=$ gaussian standard deviation coefficient

$\mathrm{g}_{1}$ and $\mathrm{g}_{2}$ are gaussian distrbance factors

$$
\begin{aligned}
& g_{1}=\mathrm{e}^{\frac{-0.5 y^{2}}{\sigma_{y}^{2}}} \\
& g_{2}=\mathrm{e}^{\frac{-0.5(z-H)^{2}}{\sigma_{z}^{2}}+\frac{-0.5(z+H)^{2}}{\sigma_{z}^{2}}}
\end{aligned}
$$

where $\quad \mathrm{z}=$ altitude

$\mathrm{H}=$ real smokestack height

The real smokestack height is higher than the physical height due to the gas upward push. So the $\mathrm{H}$ value is equal to the physical height plus $\Delta \mathrm{H}$ depending on the gas and environment temperature, the gas speed and the stack diameter. The gaussian standard deviation coefficient depend on the distance from the source point, meteorological conditions, wind velocity and atmospheric stability, and can be obtained by Pasquill stability categories (Pasquill, 1961; Hemond \& Fechner, 2014)

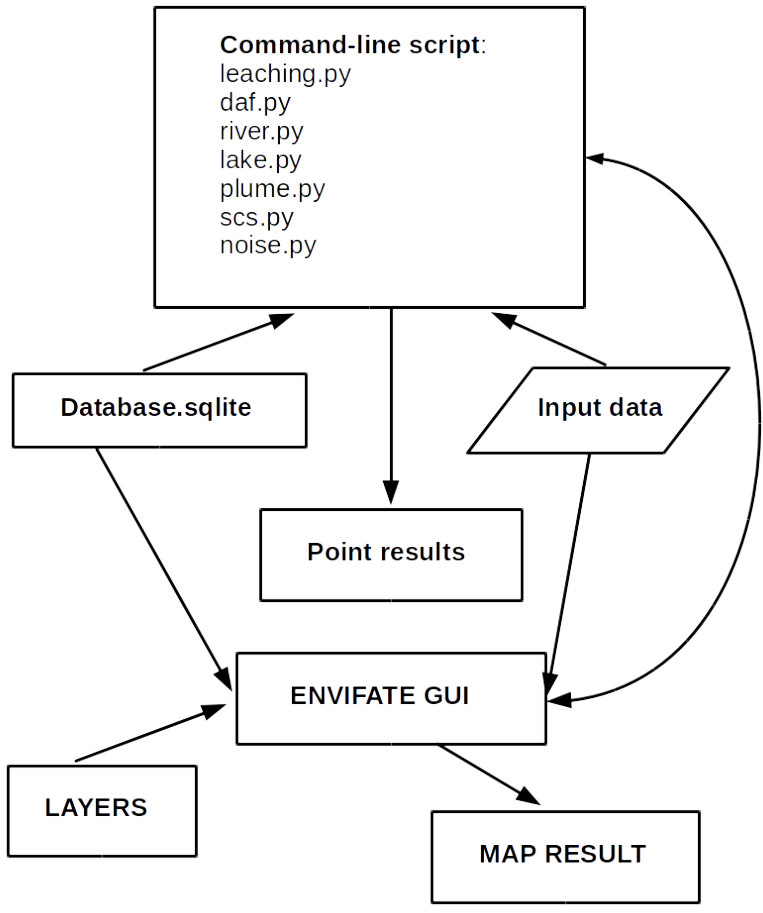

Figure 1. Logic framework of ENVIFATE

\subsection{Architecture}

The architecture of ENVIFATE is made up of a Sqlite database that contains the chemical and physical parameters of the potentially pollutting substance classified by ISPRA and needed to run the ENVIFATE modules. ENVIFATE core functions are command-line scripts that provide a point result and that can be run from a terminal or called from third part applications like Grass GIS (Grass Development Team, 2017). The ENVIFATE Graphical User Interface (GUI) applies these core functions to a lattice of points in a two dimensional space and saves the results to a two dimensional numpy vector that is then converted to a raster map. This feature permits to obtain a high level of scalability and modularity (Fig. 1).

The external libraries used in ENVIFATE are: i) gdal/ogr python bindings for the management of the vector and raster geospatial data, ii) math and numpy for data computation and iii) matplotlib for graph rapresentation.

The GUI gathers in a single window all the models and submodels available in ENVIFATE. It is written using the pyQt libraries and automatically generates the requested input depending on the loaded module. An example of GUI for the groundwater module is shown in fig. 2 .

\section{EXPECTED RESULTS}

ENVIFATE produces 2 types of results: spatial results and time results.

Spatial results consist in raster maps with resolution and extension pre-determined by the operator. The output of the 
river pollutant dispersion module contains a polyline whose segments have a length corresponding to the spatial resolution of the raster maps. The estimated concentration for each segment is associated to its starting point.

Currently, tests for the validation of the models are carried out along with the system development. So far, internal tests in single points have provided congruent results. However, tests with experimental data are needed to assess models' soundness. Figure 3 shows an example of results of the application of the groundwater model to a scenario composed by the following values: $1 \mathrm{~kg}$ of Tetracloroetilene, source of pollution with an extension equal to $10 \mathrm{sq} \mathrm{m}$, groundwater layer 10 meter deep and a $15.8 \mathrm{~m}$ deep, $2 \mathrm{~m}$ thick, mixing area ; the precipitation value is of about $730 \mathrm{~mm} /$ year (a value aligned to the real values of a Mediterran Italian city) and stream direction is 67 degrees with respect to the north direction. The red line indicates the study area chosen by the operator.

Figure 4 shows an example of atmospheric dispersion coming from a smokestack of $80 \mathrm{~m}$ of height, with an emission rate of 1 kg per hour. The map shows the pollutant ground concentration directly linked to the topographic features and the atmospheric stability. The grey line indicates the study area chosen by the operator.

Figure 5 shows a river contamination caused by an injection of 20,000 grams of benzene in a meter wide torrent, in a mountain region; the map shows the situation 10 minutes after the pollutant release in the point represented in blue. It is possible to notice the effects of downtream movement and smoothing of the peak of concentration (in purple).

ENVIFATE can also provide a temporal analysis, i.e. an evaluation of the level of decay of substance concentration depending on the time passed from the injection.

Figure 6 shows the variation of the concentration peak depending on the analysis time: 10 minute (green), 15 minutes (red) and 20 minutes (blue).

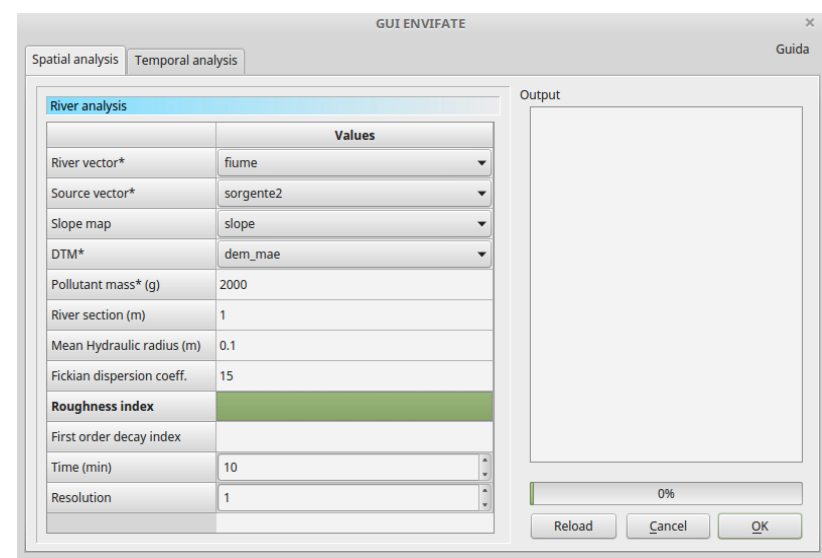

Figure 2. An example of ENVIFATE GUI.

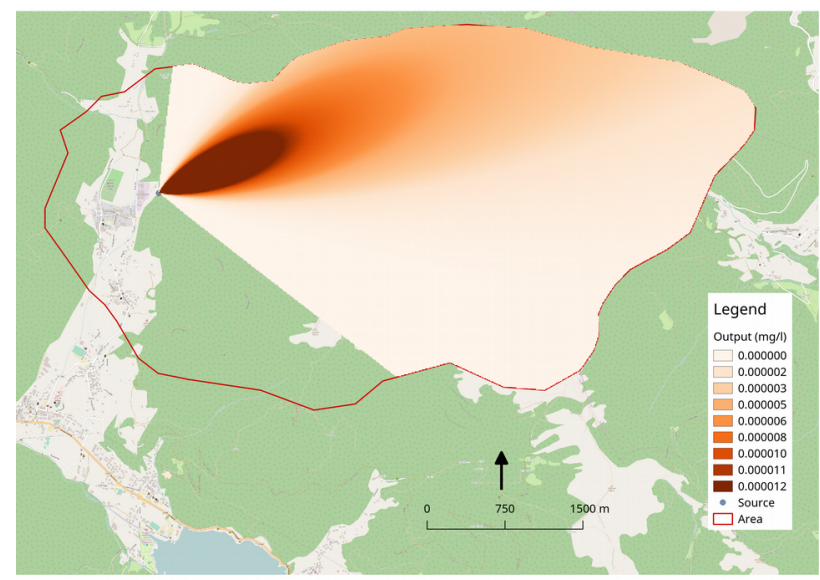

Figure 3. Example of output for the groundwater module; the concentration of Tetrachloroethylene is evaluated for the area inside the red line after the dispersion of $1 \mathrm{~kg}$ of substance.

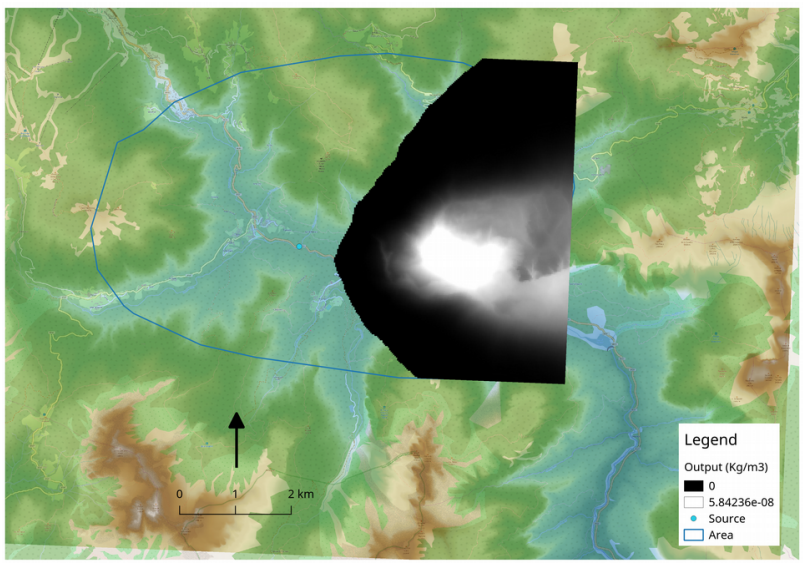

Figure 4. Example of output for the atmospheric module; pollutant ground concentration is evaluated for the area inside the black line for a $80 \mathrm{~m}$ chimney releasing $11 \mathrm{Kg} / \mathrm{h}$ of substance. 


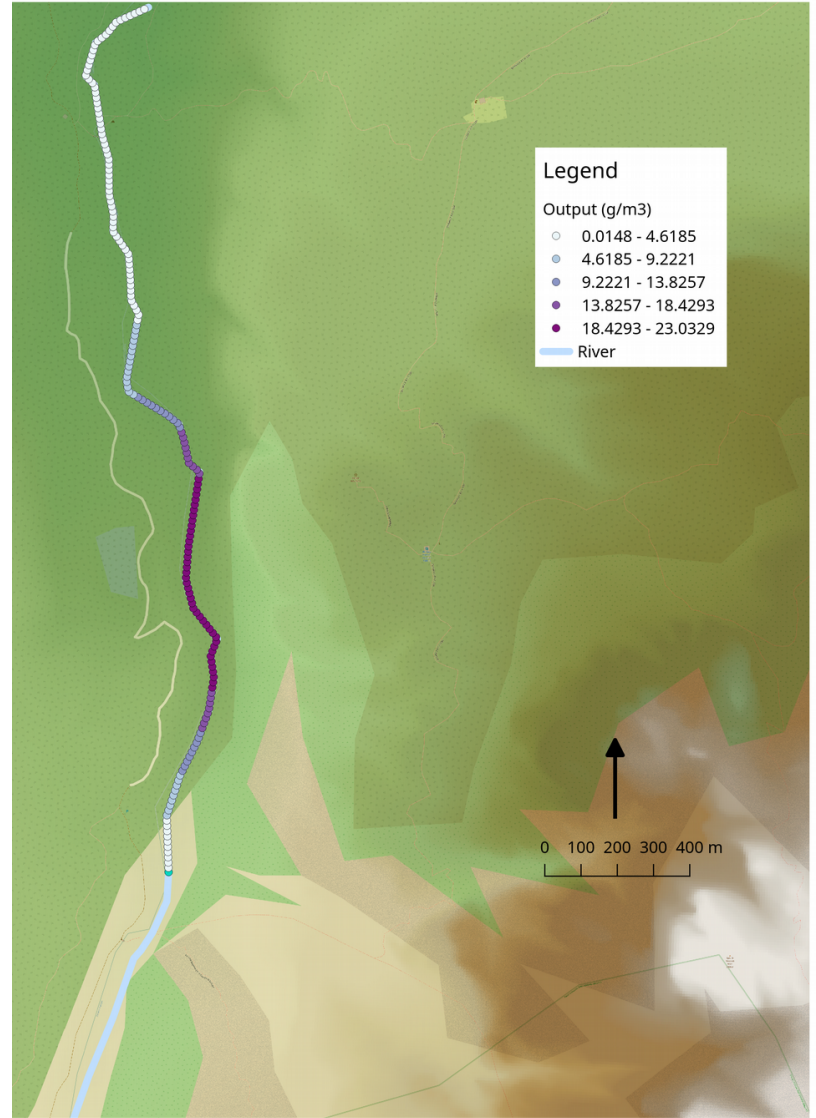

Figure 5. Example of output from the river module. Concentration of benzene 10 minutes after the release of 20000 grams in the point represented in blue.

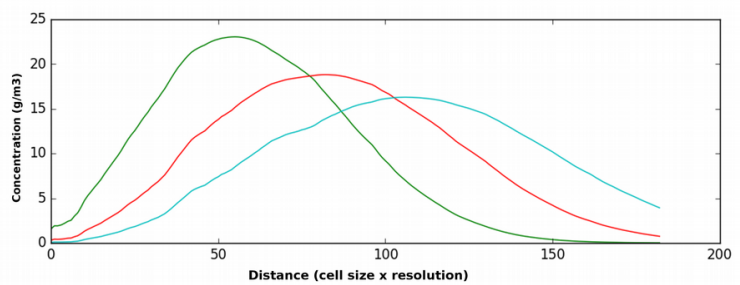

Figure 6. Example of the temporal variation of the concentration peak in a river contamination scenario

\section{CONCLUSIONS}

ENVIFATE is an attempt to create a set of tools that can be quickly used by technicians and planners to simulate environmental contamination scenarios and estimate concentrations of pollutants across different environmental matrices. One of the main goals in the ENVIFATE development is the use and development of completely open source code, so anyone can modify, use or improve it according to their needs. Furthermore, the analytical models on which the forecast is based are statistically robust and well-documented. Currently most of the software in this field is not open source or requires such level of preparation to make it very difficult to use for anyone who is not a specialized technician. Obviously, this does not mean that ENVIFATE can work without appropriate input data: as in all simulation models, the "garbage in - garbage out” principle holds, so if random values are inserted, random results will be produced.

However, ENVIFATE does not substitute more complex models but it provides an intermediate analysis step, so that it is possible to understand if a contamination risk exists, using a highly conservative approach that privileges the precaution principle. If ENVIFATE indicates the existaence of a potential risk, further investigations together with the application of more sophisticated models for a more in deep analysis is needed.

\section{REFERENCES}

ASTM E1739 - 95 (2015). Standard Guide for Risk-Based Corrective Action Applied at Petroleum Release Sites

Domenico P.A. e Schwartz F.W., (1998), Physical and Chemical Hydrogeology, John Wiley and Sons, New York.

Forouzanfar, M. H., Alexander, L., Anderson, H. R., Bachman, V. F., Biryukov, S., Brauer, M., ... \& Delwiche, K. (2015). Global, regional, and national comparative risk assessment of 79 behavioural, environmental and occupational, and metabolic risks or clusters of risks in 188 countries, 1990-2013: a systematic analysis for the Global Burden of Disease Study 2013. The Lancet, 386(10010), 2287-2323.

GRASS Development Team, (2017). Geographic Resources Analysis Support System (GRASS) Software, Version 7.2. Open Source Geospatial Foundation.

Gulliver, J., de Hoogh, K., Fecht, D., Vienneau, D., \& Briggs, D. (2011). Comparative assessment of GIS-based methods and metrics for estimating long-term exposures to air pollution. Atmospheric environment, 45(39), 7072-7080.

Haynes, W., (1954). American Chemical Industry-A History, vol. III. D. Van Nostrand, New York.

Hemond, Harold F., and Elizabeth J. Fechner., (2014) Chemical fate and transport in the environment. Elsevier.

ISPRA, “Criteri metodologici per l'applicazione dell'analisi assoluta di rischio ai siti contaminati ”, (2008), available at: www. isprambiente.it.

Lelieveld, J., Evans, J. S., Fnais, M., Giannadaki, D., \& Pozzer, A., (2015). The contribution of outdoor air pollution sources to premature mortality on a global scale. Nature, 525(7569), 367371.

Pasquill, F., (1961): The estimation of the dispersion of windborne material. Meteor. Mag.,90, 33-49.

QGIS Development Team, (2017). "QGIS geographic information system." Open Source Geospatial Foundation Project.

Schwarzenbach, R. P., Egli, T., Hofstetter, T. B., von Gunten, U., \& Wehrli, B., (2010). Global water pollution and human health. Annual Review of Environment and Resources, 35, 109136.

Tarlock, D. A., (2009). History of Environmental Law. Environmental Laws and Their Enforcement.Vol. 1. Encyclopedia of Life Support Systems. 